\title{
Peningkatan Kompetensi Teknologi Komunikasi untuk Lomba Virtual pada Guru Sekolah Dasar di Surabaya Melalui Pelatihan Editing Video
}

\author{
Vinda Maya Setyoningrum ${ }^{*}$, Danang Tandyomano², Tsyuroyya ${ }^{3}$, Mutiah $^{4}$, Anam Miftakhul Huda \\ 1,2,3,4,5 Ilmu Komunikasi, Universitas Negeri Surabaya, Jl. Ketintang, Ketintang, Kec. Gayungan, Kota \\ Surabaya, Jawa Timur 60231
}

Correspondence: vindasetiangrum@unesa.ac.id

Received: 30 Juni 2021 - Revised: 01 Agustus 2021 - Accepted: 16 Agustus 2021

\begin{abstract}
Abstrak. Melalui pelatihan video editing diharapkan pendidik akan mampu memberikan materi pembelajaran yang menarik dan kreatif bagi peserta didik agar peserta didik lebih fokus dan tertarik menerima materi yang disampaikan oleh gurunya. Kualitas pendidik di Kota Surabaya masih perlu ditingkatkan termasuk dalam keterampilan membuat video auidio visual, sehingga diperlukan adanya pelatihan dan bimbingan secara khusus agar tenaga pendidik dapat memiliki skill dalam membuat dan mengedit media pembelajaran berbasis video supaya guru dapat lebih kreatif untuk membuat presentasi materi pembelajaran. Tahapan dalam proses kegiatan pengabdian ini yaitu tahap persiapan, pelaksanaan, evaluasi, dan pembuatan laporan. Hasil dari kegiatan pengabdian ini yaitu peserta pengabdian mampu menggunakan aplikasi editing video, peserta pengabdian berhasil membuat suatu produk video pembelajaran yang menarik dan inovatif, peserta pengabdian antusias untuk mengasah kemampuan eiditing video dengan mengikuti kegiatan perlombaan video editing.
\end{abstract}

Kata kunci: Editing, video, guru.

Citation Format: Setyoningrum V.M., Tandyomano, D., Tsyuroyya, Mutiah \& Huda, A.M (2021). Peningkatan Kompetensi Teknologi Komunikasi untuk Lomba Virtual pada Guru Sekolah Dasar di Surabaya Melalui Pelatihan Editing Video. Prosiding Seminar Nasional Abdimas Ma Chung (SENAM), 171-179. 


\section{PENDAHULUAN}

Pada hakikatnya proses kegiatan belajar dan mengajar masuk dalam proses komunikasi. Proses komunikasi yaitu proses menyampaikan pesan dari sumber pesan melalui media tertentu ke penerima pesan. Pesan yang dikomunikasikan adalah isi pembelajaran yang terdapat di dalam kurikulum yang disampaikan oleh guru melalui simbol-simbol komunikasi baik menggunakan simbol verbal berupa kata-kata lisan maupun tertulis, dapat juga menggunakan simbol non verbal atau visual. Penyampaian materi menggunakan media pembelajaran yang baik diharapkan dapat meningkatkan pemahaman siswa terhadap materi pembelajaran yang disampaikan (Nurhikmah, \& Haling, 2020). Maka dari itu demi mengoptimalkan kegiatan pembelajaran maka proses kegiatan pembelajaran perlu didukung dengan penggunaan media pembelajaran yang menarik sehingga mudah dipahami oleh siswa. Sebagaimana yang disampaikan oleh Achsin (1993) dalam bukunya, beliau menyampaikan pendapat bahwa penggunaan media pembelajaran dipercaya dapat menarik dan memperbesar perhatian peserta didik terhadap materi pembelajaran yang disampaikan.

Sebagai seorang pendidik, guru diharapkan dapat merancang media pembelajaran yang kreatif, inovatif, efektif dan efisien guna menunjang kegiatan pembelajaran. Salah satu jenis media pembelajaran yang mampu meningkatkan keaktifan dari peserta didik dalam proses pembelajaran yaitu dengan menggunakan media pembelajaran berupa video. Banyak sekali manfaat yang di dapat dari penggunaan video sebagai media pembelajaran yang salah satunya yaitu dapat membantu menambah minat siswa dalam mempelajari materi yang diberikan oleh guru karena di dalam video siswa dapat menyimak materi sekaligus melihat gambar berupa animasi. Media video merupakan salah satu jenis media audio visual. Media audio visual sendiri memiliki arti sebagai media yang dalam penggunaannya mengandalkan dua panca indera manusia yaitu indera pendengaran dan indera penglihatan (Mustikasari, 2016). Media audio visual merupakan salah satu media yang dapat digunakan dalam proses pembelajaran dengan metode menyimak. Arsyad (2011) dalam penelitiannya menyatakan bahwa video merupakan gambaran-gambaran dalam frame, dimana frame diproyeksikan melalui lensa proyektor secara mekanis sehingga pada layar terlihat gambar hidup.

Video mempunyai kemampuan untuk melukiskan gambar hidup dan dibarengi dengan adanya suara-suara yang membuat media pembelajaran video memiliki daya tarik 
tersendiri bagi peserta didik. Video sebagai media audio visual menggabungkan beberapa indera manusia, peserta didik tidak hanya dapat mendengarkan penjelasan dari gurunya akan tetapi peserta didik juga dapat melihat gambaran-gambaran dari materi yang ditampilkan oleh gurunya dalam media pembelajaran tersebut. Berdasarkan penelitian yang pernah dilakukan oleh Baugh dalam Arsyad (2002) diketahui bahwa kurang lebih sebanyak 90\% untuk memperoleh hasil belajar seseorang melalui indera pandang, sebesar 5\% diperoleh melalui indera dengar dan sebesar 5\% diperoleh melalui indera lainnya. Maka dari itu diperlukan suatu upaya guna meningkatkan mutu pendidikan melalui pemanfaatan media dalam proses pembelajaran di kelas. Salah satunya yaitu dengan menggunakan media pembelajaran berbasis video.

\section{MASALAH}

Di tengah mewabahnya pandemic Covid-19 memicu pendidik untuk lebih kreatif dalam menciptakan suasana belajar daring yang cenderung baru untuk di laksanakan. Terciptanya suasana yang baik akan memberikan pengalaman belajar yang lebih bermakna bagi peserta didik. Melalui pelatihan video editing diharapkan pendidik akan mampu memberikan materi pembelajaran yang menarik dan kreatif bagi peserta didik agar peserta didik lebih fokus dan tertarik menerima materi yang disampaikan oleh gurunya.

Kualitas pendidik di Kota Surabaya masih perlu ditingkatkan termasuk dalam keterampilan membuat video audio visual, sehingga diperlukan adanya pelatihan dan bimbingan secara khusus agar tenaga pendidik dapat memiliki skill dalam membuat dan mengedit media pembelajaran berbasis video supaya guru dapat lebih kreatif untuk membuat presentasi materi pembelajaran.

Penyelenggaraan pelatihan video editing bagi Guru Sekolah Dasar (SD) secara daring diikuti oleh 50 guru SD yang tersebar di 31 Kecamatan se-Kota Surabaya. Peserta yang mengikuti kegiatan tersebut merupakan perwakilan dari masing-masing sekolah yang berada di Kecamatan se-Kota Surabaya. Pelatihan yang merupakan program pengabdian kepada masyarakat (PKM) itu bertujuan untuk meningkatkan kemampuan guru Sekolah Dasar (SD) dalam bidang teknologi komunikasi pendidikan khususnya dalam memanfaatkan, mengedit dan mendesain video untuk kebutuhan pembelajaran daring selama pandemi. 
Solusi dari diadakannya kegiatan PKM ini adalah untuk melatih guru SD di Kota Surabaya agar mampu menggunakan dan memanfaatkan media pembelajaran berbasis video dalam pembelajaran serta mengetahui aplikasi yang dapat digunakan, yang dapat meningkatkan proses belajar mengajar yang efektif dan efisien dan tentunya lebih menarik.

\section{METODE PELAKSANAAN}

Kegiatan pengabdian ini dilaksanakan pada hari Senin, 05 Juni 2021. Kegiatan ini di ikuti oleh 50 guru yang tersebar di 31 Kecamatan se-Kota Surabaya. Pelaksanaan kegiatan Pengabdian Kepada Masyarakat (PKM) ini menggunakan metode yang bervariasi. Pemecahan masalah dalam kegiatan ini dilakukan melalui beberapa tahapan yaitu:

1. Tahap persiapan.

Pada tahapan ini anggota tim PKM menyiapkan proposal untuk kegiatan pengabdian. Kemudian dilanjutkan dengan pengajuan izin untuk pelaksanaan kegiatan pengabdian. Selanjutnya mempersiapkan materi atau bahan untuk pelaksanaan kegiatan pengabdian

2. Tahap Pelaksanaan.

Pada tahapan ini dimulai dengan registrasi peserta, pembukaan, penyajian materi, pelatihan dan penutupan.

3. Tahap Evaluasi.

Pada tahap ini dilakukan sesi tanya jawab tentang materi PKM untuk mengetahui tingkat kepahaman peserta pelatihan sesudah dan sebelum diadakannya pelatihan.

4. Tahap Pembuatan Laporan.

Pada tahapan ini anggota PKM menyusun laporan kegiatan PKM.

\section{HASIL DAN PEMBAHASAN}

Pelatihan video editing bagi Guru Sekolah Dasar (SD) di Kota Surabaya dilakukan secara virtual pada hari Senin, 05 Juni 2021. Kegiatan ini diikuti oleh 50 guru yang tersebar di 31 Kecamatan se-Kota Surabaya. Prosesi kegiatan pengabdian dilakukan dalam dua sesi acara. Sesi pertama perserta PKM memperoleh materi tentang "Vidio sebagai Media Pembelajaran" yang disampaikan oleh Ketua Program Studi Ilmu Komunikasi dan Pakar Komunikasi Pendidikan Universitas Negeri Surabaya (UNESA) yaitu Dr. Danang Tandyonomanu, M.Si. Kemudian dilanjut dengan pemberian materi mengenai "Scrip Writing and Storyboard" yang disampaikan oleh Tsuroyya, S.S., M.A yang merupakan Dosen Ilmu Komunikasi Universitas Negeri Surabaya (UNESA). Selanjutnya Dr. Anam 
Miftakhul Huda, S.Kom., M.Ikom, yang merupakan Dosen Ilmu Komunikasi di Universitas Negeri Surabaya (UNESA) juga menyampaikan materi mengenai "Tren Perlombaan Virtual”, materi ini disampaikan guna membekali guru mengenai pemahaman tentang kompetensi video editing.

Pada sesi kedua dilanjutkan dengan pemberian pelatihan teknis dalam video editing. Pada sesi ini peserta kegiatan PKM diberikan pelatihan mengenai video editing yang disampaikan oleh Nadya Yudo Wiranti, S.I.Kom. yang merupakansalah satu tim teknis dan kreatif UPT Humas Universitas Negeri Surabaya (UNESA). Pada sesi ini guru dibekali cara yang mudah untuk mengedit video dengan memanfaatkan aplikasi di smartphone seperti aplikasi Inshot, Capcut dan Canva.

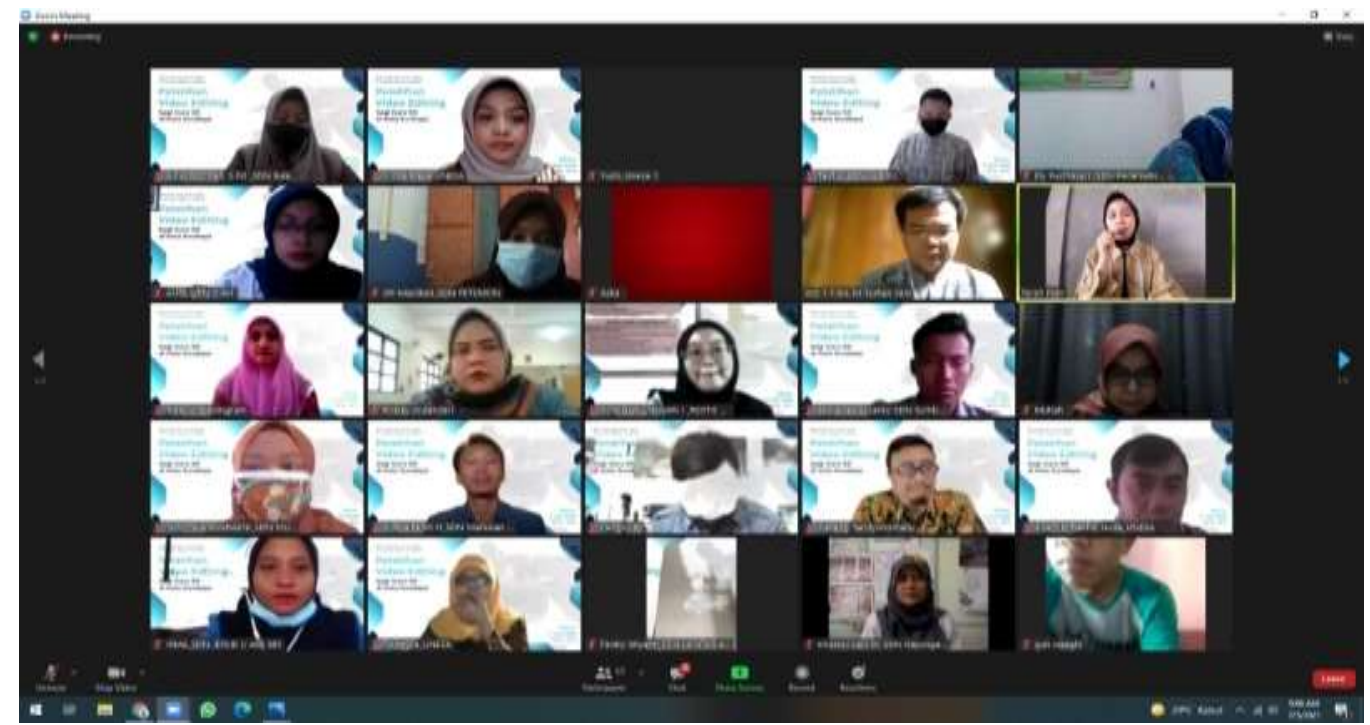

Gambar 1. Tahap Penyampaian Materi PKM secara virtual

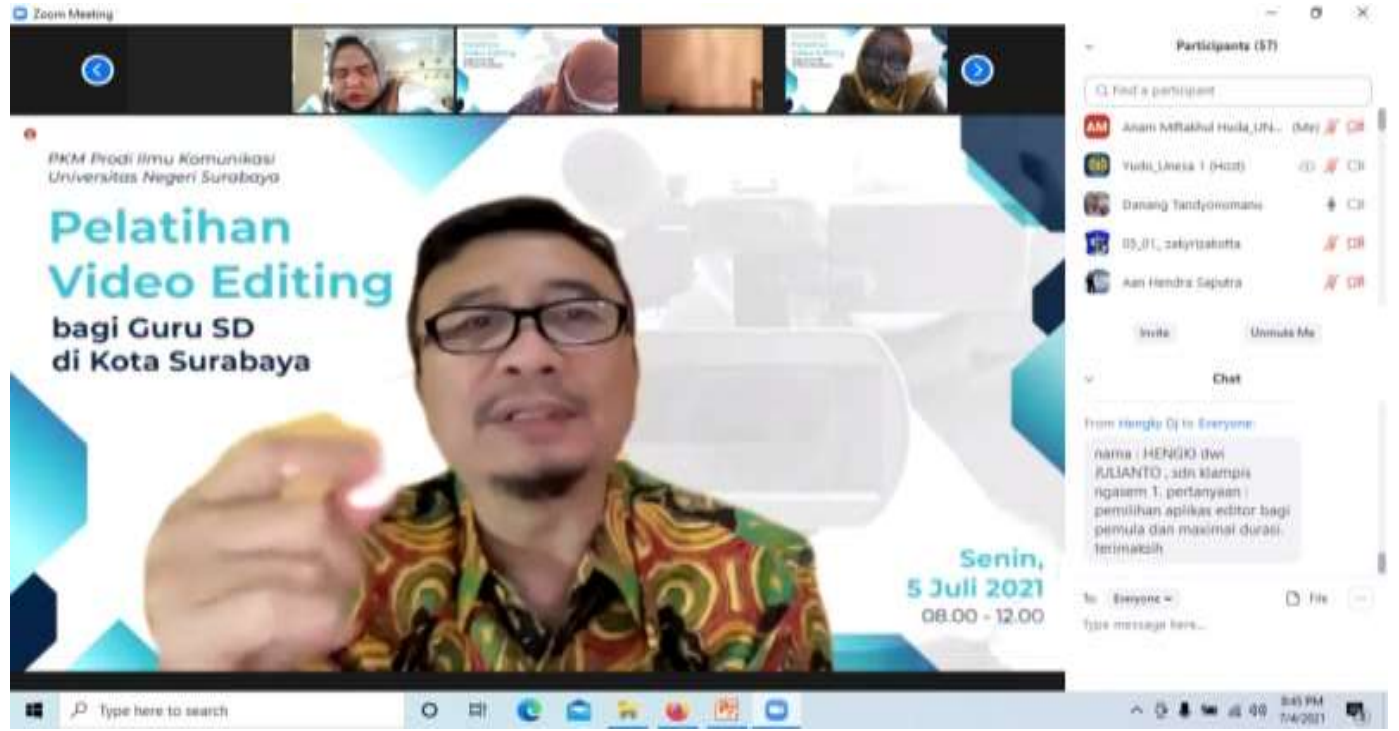

Gambar 2. Pelatihan Vidio Editing Secara Virtual 
Kegiatan pengabdian berupa pelatihan video editing dirasa sesuai dengan kebutuhan guru di lapangan. Pada saat ini guru dihadapkan dengan kondisi dimana peserta didik sangat rawan mengalami rasa bosan dan jenuh dalam menerima materi pembelajaran sehingga berdampak pada motivasi belajar, proses belajar dan hasil belajar. Karena hal tersebut guru dituntut untuk lebih aktif, kreatif dan inovatif dalam menyampaikan materi pembelajaran kepada para peserta didik. Salah satu cara yang dapat digunakan oleh guru untuk memberikan materi pembelajaran yang lebih fresh dan menarik yaitu guru dapat memanfaatkan media pembelajaran berbasis video, guru dapat membuat, mengedit dan memanfaatkan video untuk menunjang kebutuhan pembelajaran (Limbong, \& Simarmata, 2020).

Output yang dihasilkan dari kegiatan pengabdian kepada masyarakat yang dilakukan oleh dosen Prodi Ilmu Komunikasi Universitas Negeri Surabaya (UNESA) melalui pelatihan editing video yaitu para peserta diarahkan untuk mengikuti perlombaan video PKM yang diadakan oleh Prodi Ilmu Komunikasi dengan tema khusus yaitu sebagai berikut :

1) Pendidikan Kesehatan Masyarakat untuk Mencegah Penyebaran Covid-19 di Sekolah, Komunitas, dan Keluarga.

2) Memaksimalkan Penggunaan Pembelajaran ICT di dalam (transformasi) Kelas dan Konten ICT untuk Pendidikan

Dari perlombaan ini diambil 3 (tiga) pemenang yang masing-masing mendapatkan hadiah. Video terbaik pertama mendapatkan hadia sebesar Rp. 1 juta, video terbaik kedua mendapatkan hadiah 3 (tiga) peserta yang vidionya masuk kedalam video terbaik pertama mendapatkan hadiah sebesar Rp. 1 juta untuk juara pertama, Rp. 750 ribu dan untuk video terbaik ke tiga mendapatkan hadiah sebesar Rp. 500 ribu.

Sebagian peserta kegiatan PKM antusias untuk mengikuti perlombaan ini.Dari 50 peserta pengabdian yang mengikuti kegiatan workshop secara virtual, sebanyak 25 peserta yang mengikuti lomba video PKM. 25 peserta tersebut merupakan bapak/ibu dewan guru Sekolah Dasar (SD) di Surabaya yang telah mengirimkan email ke ikom.fish@unesa.ac.id. Berdasarkan hasil penilaian yang telah dilaksanakan oleh dewan juri dalam lomba video PKM Prodi Ilmu Komunikasi 2021 telah diputuskan 3 pemenang lomba video PKM yaitu sebagai berikut : 
1) Juara 1 yaitu Ibu Dyah Kusumasari yang merupakan guru dari SDN Kutisari I Surabaya. Judul video yaitu "Pemanfaatan ICT dalam Pembelajaran di SDN Kutisari I Surabaya"

2) Juara 2 yaitu Ibu Khairun Nisa dengan judul video "Lomba Video Unesa"

3) Juara 3 yaitu Bapak Aan Saputra dari SDN Benowo 1 Surabaya. Judul video yaitu "Pendidikan Covid 19"

Tidak hanya berhenti sampai disini, kegiatan PKM ini masih berlanjut dengan menetapkan sebanyak 10 peserta dengan video terbaik yang akan mendapatkan pendampingan khusus untuk mengikuti kompetisi video tingkat Asia Tenggara dalam ajang SEAMEO-Japan ESD Award 2021. Hal ini dipilih karena perlomban tersebut merupakan kesempatan yang bagus dan harus dimanfaatkan oleh guru, karena dengan mengikuti perlombaan ini dapat digunakan sebagai motivasi sekaligus jalan untuk mengukir prestasi.

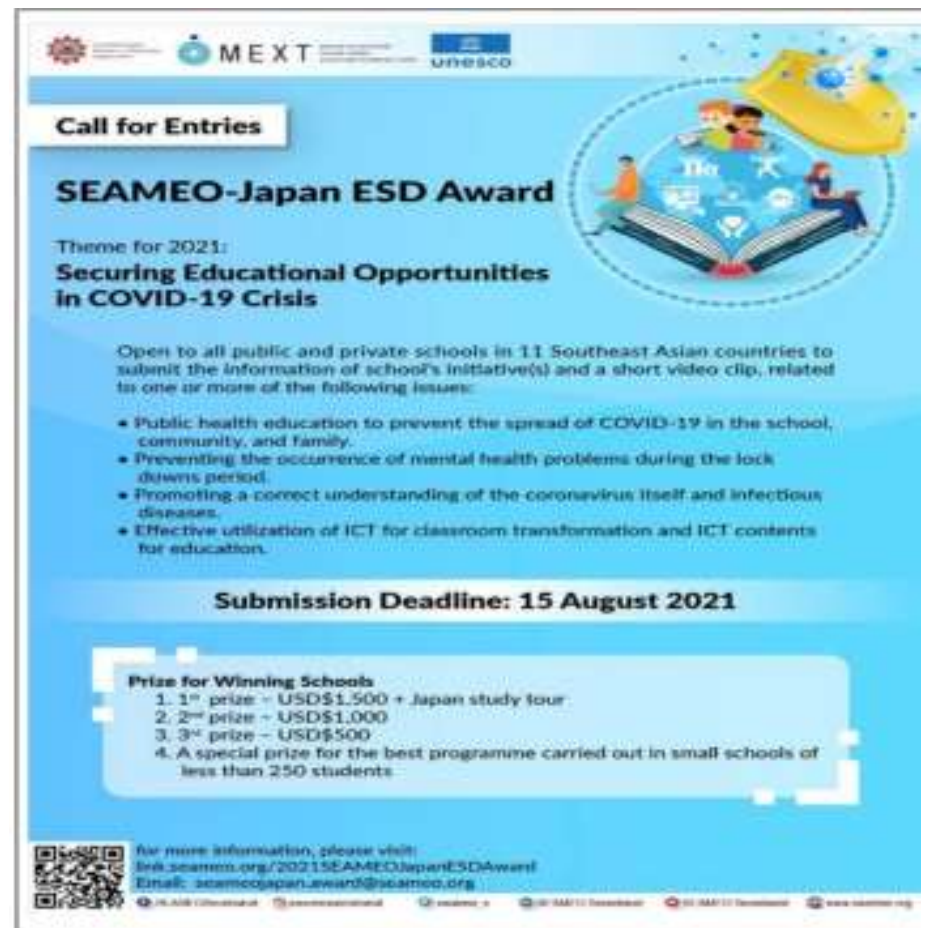

Gambar 3. Poster Lomba Video SEAMEO-Japan ESD Award 2021

Adapun 10 peserta yang masuk dalam daftar peserta pendampingan lomba video SEAMEO-Japan ESD Award 2021 adalah sebagai berikut :

1) Dyah Kusumasari. Asal sekolah dari SDN Kutisari I Surabaya. Judul vidio "Pemanfaatan ICT dalam Pembelajaran di SDN Kutisari I Surabaya"

2) Khairun Nisa dengan video yang berjudul "Lomba Video Unesa" 
3) Aan Saputra. Asal sekolah dari SDN Benowo I Surabaya. Judul video "Pendidikan Covid 19"

4) Regina Septiria dengan video berjudul "Ayo Patuhi Protokol Kesehatan"

5) Eny Diyanti dengan video berjudul "Kenalan dengan Corona"

6) Khusnul Laili. Asal sekolah dari SDN Gayungan II Surabaya. Judul video "Kelas Virtual"

7) Umi Farida dari SDN Kapasan V

8) Rudi Hartono dengan video berjudul "Tugas Video Unesa"

9) Nanang Fauzi dengan video berjudul "Pembelajaran Daring"

10) Rizky Widyaningrum dengan video berjudul "Media Pembelajaran"

Salah satu inovasi pembelajaran daring yang dapat dimanfaatkan dan dikembangkan oleh pendidik ada media pembelajaran berbasis video. Video memiliki beberapa keunggulan daripada media pembelajaran lainnya. Video dapat menghadirkan seluruh fungsi media mulai dari menyampaikan informasi, mendidik dan bahkan memberikan hiburan serta dapat memadukan seluruh unsur media baik audio maupun visual (Wina, 2011). Selain hal tersebut, video pembelajaran juga dapat memudahkan guru dalam menyampaikan materi pembelajaran dan memudahkan siswa dalam belajar. Kemudian video pembelajaran juga dapat memberikan pengalaman lebih nyata kepada siswa, serta dapat lebih menarik perhatian dan minat siswa dalam belajar. Karena melalui video dapat sekaligus menyampaikan informasi, demonstrasi, materi procedural seperti langkahlangkah dalam tutorial, dan bisa juga digunakan untuk pembelajaran afeksi (Nurdin, Ma’aruf, Amir, Risnawati, Noviarni, \& Azmi (2019).

Dari seluruh rangkaian kegiatan Pengabdian Kepada Masyarakat (PKM) melalui workshop dan pelatihan video editing ketahui bahwa pelatihan video editing ini sangat bermanfaat bagi tenaga pendidik. Sebab, pembelajaran menggunakan video sangat menyenangkan bagi siswa dan dapat dijadikan sebagai salah satu langkah inovatif dalam memaksimalkan pembelajaran daring selama masa pandemi. Akan tetapi tidak bisa dipungkiri bahwasanya pembelajaran lewat video sangat memakan kuota internet dan bisa menjadi beban bagi peserta didik.

\section{KESIMPULAN}

Berdasarkan hasil kegiatan Pengabdian Kepada Masyarakat (PKM) melalui pelatihan video editing secara virtual yang telah dilaksanakan dapat diperoleh kesimpulan 
bahwa 1) Peserta pengabdian mampu menggunakan aplikasi editing video, 2) Peserta pengabdian berhasil membuat suatu produk video pembelajaran yang menarik dan inovatif, 3) Peserta pengabdian antusias untuk mengasah kemampuan eiditing video dengan mengikuti kegiatan perlombaan video editing.

\section{UCAPAN TERIMA KASIH}

Ucapan terimakasih kami sampaikan kepada PNBP Fakultas Ilmu Sosial dan Hukum Universitas Negeri Surabaya yang telah mendanai kegiatan ini. Tak lupa kami sampaikan terimakasih kepada keseluruhan pihak yang terlibat aktif dalam kegiatan pengabdian ini.

\section{DAFTAR PUSTAKA}

Achsin, A. (1993). Media Pembelajaran dalam Proses Belajar Mengajar Masa Kini. Ujungpandang: IKIP Ujungpandang.

Arsyad, A. (2002). Media Pembelajaran Jakarta: Raja Grafindo Persada.

Azhar, A. (2011). Media pembelajaran. Jakarta: Rajawali Pers.

Limbong, T., \& Simarmata, J. (2020). Media dan Multimedia Pembelajaran: Teori \& Praktik. Yayasan Kita Menulis.

Mustikasari, R. (2016). Penggunaan Media Audio Visual (Video) Untuk Meningkatkan Hasil Belajar Dalam Pembelajaran Ips Materi Permasalahan Sosial (Penelitian Tindakan Kelas pada Siswa Kelas IV SD Negeri Cijagra 2 Kecamatan Bojongsoang) (Doctoral dissertation, FKIP UNPAS).

Nurdin, E., Ma'aruf, A., Amir, Z., Risnawati, R., Noviarni, N., \& Azmi, M. P. (2019). Pemanfaatan video pembelajaran berbasis Geogebra untuk meningkatkan kemampuan pemahaman konsep matematis siswa SMK. Jurnal Riset Pendidikan Matematika, 6(1), 87-98.

Nurhikmah, H., \& Haling, A. (2020, January). Peningkatan Kompetensi Guru melalui Pelatihan Media Video di Kabupaten Sinjai. Seminar Nasional Pengabdian Kepada Masyarakat, Vol. 2019, No. 11.

Sanjaya, W. (2011). Perencanaan \& Desain Sistem Pembelajaran. Jakarta: Kencana Prenadamedia Group.

cc) (9)

(C) 2021 by authors. Content on this article is licensed under a Creative Commons Attribution 4.0 International license. (http://creativecommons.org/licenses/by/4.0/). 